\title{
Mechanistic explanations and components of social mechanisms
}

\author{
Saúl Pérez-González \\ Universitat de València
}

\begin{abstract}
The past two decades have witnessed an increase in interest in social mechanisms and mechanistic explanations of social macro-phenomena. This paper addresses the question of what the components of social mechanisms in mechanistic explanations of social macro-phenomena must be. Analytical sociology's initial position and the main new proposals by analytical sociologists are discussed. It is argued that all of them are faced with outstanding difficulties. Subsequently, a minimal requirement regarding the components of social mechanisms is introduced. It is held that a component of a social mechanism in a mechanistic explanation of a social macro-phenomenon must not have the explanandum phenomenon as a part of it.
\end{abstract}

Keywords: mechanism; scientific explanation; analytical sociology; structural individualism.

\section{Introduction}

The past two decades have witnessed an increase in interest in social mechanisms (i.e. mechanisms for social macro-phenomena) and mechanistic explanations of social macro-phenomena. This increase has been related with the development of analytical sociology. ${ }^{1}$ Analytical sociology is a methodological movement within sociology that underlines the relevance of social mechanisms (Elster 1989, 2007; Hedström 2005; Hedström and Bearman 2009b; Hedström and Ylikoski 2010). ${ }^{2}$ Analytical sociologists claim that the main aim of sociology should be to explain social macro-phenomena (e.g. racial segregated neighbourhoods) by means of the mechanisms that are responsible for them (Hedström 2005). They also consider that the notion of mechanism is helpful for addressing other issues such as causation and scientific knowledge growth (Hedström and Ylikoski 2011).

The aim of this paper is to address the question of what the components of social mechanisms in mechanistic explanations of social macro-phenomena must be (henceforth, "the question of components"). Addressing this question is crucial for the development of the mechanistic account of scientific explanation in social science. Mechanistic explanations must specify the mechanisms responsible for the explanandum phenomena, which requires identifying their components. In that kind of explanations, it is fundamental to detail how the components of the mechanism together give rise to the phenomenon. Consequently, knowing what the components of social mechanisms in mechanistic explanations of social macro-phenomena must be is essential for building mechanistic explanations. Throughout the paper, in order to address the question of components, legitimate mechanism-based explanations of social macro-phenomena will usually be taken as reference. Those explanations are one of the main guidelines for developing and evaluating potential

\footnotetext{
${ }^{1}$ In this paper, I will focus on analytical sociology, which is the main approach in the discourse on social mechanisms and mechanistic explanations in social science. Nevertheless, it should be noted that there are several authors who have addressed those issues from alternative perspectives (see Bunge 1997, 2004; Tilly 2000, 2001, 2004; Abbott 2007; Gross 2009).

${ }^{2}$ For an exhaustive exposition of the emergence of analytical sociology and its relationship with previous proposals see (Manzo 2010).
} 
answers to that question (see, for instance, Hedström and Bearman 2009a). The structure of the paper is as follows. Section 2 presents the fundamental principles of analytical sociology, its initial position with respect to the question of components, and the main critique against that position. Sections 3 and 4 analyse the main proposals regarding the question of components that have been raised by analytical sociologists after the critiques against their initial position. It is argued that they are faced with outstanding difficulties. Section 5 introduces a minimal requirement that must be fulfilled by components of social mechanisms in mechanistic explanations of social macro-phenomena. It is held that a component of a social mechanism in a mechanistic explanation of a social macro-phenomenon must not have the explanandum phenomenon as a part of it. Finally, section 6 concludes.

\section{The fundamental principles of analytical sociology}

A core idea of analytical sociology is the principle of mechanism-based explanations. Although analytical sociology is not a completely homogenous movement, all analytical sociologists support the mechanistic account of scientific explanation. Mechanistic explanations in sociology are proposed as an alternative to covering-law explanations and statistical explanations (Hedström 2005). Both covering-law and statistical explanations are black-box explanations. ${ }^{3}$ This kind of explanations is characterized by considering that either the link between explanans and explanandum is devoid of structure or its structure has no explanatory interest (Hedström and Swedberg 1998). They do not address the processes that would allow us to understand how explanans and explanandum are actually linked.

Analytical sociologists consider that a social macro-phenomenon is explained by specifying the mechanism by which that phenomenon is brought about (Hedström 2005; Hedström and Bearman 2009b; Hedström and Ylikoski 2011). Mechanism-based explanations open up the black box that connects explanans and explanandum and detail the social cogs and wheels of the causal process through which the explanandum is produced. They oppose black-box explanations, "the mechanism should not include any glaring black boxes which simply give raise to additional why-questions" (Hedström 2005, p. 26). Unfortunately, there is no consensus on the notion of mechanism. Within the framework of analytical sociology, several notions of mechanism have been adopted (see Mahoney 2001; Hedström 2005). Nevertheless, all notions share some basic aspects (Hedström and Ylikoski 2010). First, a mechanism is always a mechanism for a phenomenon. It is identified and delimited by reference to the phenomenon for which it is responsible. Second, a mechanism involves causal aspects. It refers to causal processes in which its component entities are engaged. Third, a mechanism has a structure. A mechanism consists of a structured constellation of entities and activities. Fourth, mechanisms are nested and form a hierarchy. A mechanism at one level presupposes or takes for granted certain entities and activities, but there are often lower-level mechanisms that account for them.

An example of a mechanistic explanation of a social macro-phenomenon is Matthew J. Salganik, Peter Sheridan Dodds, and Duncan J. Watts' explanation of why successful cultural products (e.g. best-

\footnotetext{
${ }^{3}$ For other critiques against covering-law explanations and statistical explanations in social science see (Hedström 2005).
} 
selling books, hit songs...) are orders of magnitude more successful than average (Salganik et al. 2006; Salganik and Watts 2009). The authors explain this social macro-phenomenon by specifying how the behaviour of individuals produces it. Social influence is present in cultural markets, where information about the success of offered products is often available (e.g. best sellers lists). Due to the huge amount of offered cultural products, individuals are likely to follow others' choices and buy those products that are already successful. This tendency is also reinforced by structural features of many cultural markets, such as giving best-selling books more prominent in-store placement. Therefore, cumulative advantage operates. Cultural products that are successful tend to become still more successful. Initially small differences become large differences and, consequently, inequality increases. In cultural markets, social influence at the level of individuals leads to inequality of success at the macro level. In Salganik, Dodds, and Watts' work, the presence of social influence in cultural markets and its contribution to inequality of success are supported by an experimental study in an artificial cultural market (Salganik et al. 2006). They created a website in which participants listened and downloaded previously unknown songs with or without knowledge of previous participants' downloads. That experiment strongly suggested that individuals' behaviour was influenced by others' choices and that social influence contributed to inequality of success. When knowledge of previous participants' choices (and songs' popularity) was available, individuals were more likely to download popular songs (i.e. the most previously downloaded songs) than when that information was not available. Moreover, inequality of success was greater in the social-influence condition (i.e. when knowledge of previous participants' choices was available) than in the independent condition.

The other fundamental principle of analytical sociology is structural individualism (Hedström 2005; Hedström and Ylikoski 2010, 2011). It is "a doctrine according to which all social facts, their structure and change, are in principle explicable in terms of individuals, their properties, actions, and relations to one another." (Hedström and Ylikoski 2010, p. 60). Structural individualism is a weak version of methodological individualism (Udehn 2001). It considers that social macro-phenomena must be explained in terms of interactions of individual agents. Individuals are the main entities and their actions are the main activities that give rise to social macro-phenomena. However, structural individualism admits that not all explanatory facts are about individuals in the strict sense. Relations and relational structures (e.g. topologies of social networks) may be explanatorily relevant. They influence in individuals' behaviour and in social outcomes brought about. Salganik, Dodds, and Watts' (2006) explanation of inequality of success in cultural markets meets the requirements of structural individualism. The explanandum social macrophenomenon is explained in terms of individuals, their properties, actions, and relations. The authors refer to a social mechanism whose components are individual consumers, their properties (e.g. having certain taste, being influenced by others' choices...), activities (e.g. listening, buying, downloading...), and relations. It should be particularly noted that their explanation includes references to relations among individuals and relational structures, which is the main aspect that distinguishes structural individualism from other versions of methodological individualism. For instance, it is specified how individuals' choices are influenced by the way in which other individuals' behaviour is showed. It is claimed that the more highlighted is the previous behaviour of individuals, the stronger is the effect of social influence.

The principles of mechanism-based explanations and structural individualism are not considered independent. Analytical sociologists hold that the principle of mechanism-based explanations implies 
structural individualism. ${ }^{4}$ In this sense, Hedström and Ylikoski say: "The methodological individualism of analytical sociology [i.e. structural individualism] is a consequence of its account of scientific explanation, not an independent metaphysical doctrine" (2011, p. 393). Their main argument in support of that idea is that there are social mechanisms only at the individual level (Hedström and Swedberg 1998; Hedström 2005). Due to the discipline-specific relevance criteria, social mechanisms are always at the individual level. All social mechanisms are composed of individuals, their properties, actions, and relations. Higher level mechanisms, which would include glaring black-boxes, and lower level mechanisms, which would entail an excessive decomposition of their parts, would hardly be considered relevant by social scientists. Consequently, demanding mechanistic explanations would mean demanding explanations in terms of individuals, their properties, actions, and relations. Structural individualism would be an unavoidable consequence of the principle of mechanism-based explanations. According to analytical sociologists, one could not adopt the principle of mechanism-based explanations in sociology without accepting structural individualism. Supporting a mechanistic account of scientific explanation in sociology would require a commitment to the idea that a social macro-phenomenon must be explained in terms of interactions of individual agents. The commitment to structural individualism leads to an answer to the question of components: a social mechanism in an explanation of a social macro-phenomenon must be composed of individuals, their properties, actions, and relations to one another. This is the analytical sociology's initial position regarding the question of components.

In response to the analytical sociology's initial answer to the question of components, several authors have disputed the idea that the principle of mechanism-based explanations implies structural individualism (Kincaid 2004; Mayntz 2004; Vromen 2010; Wan 2012; Kaidesoja 2013). They have argued that it is unlikely to be the case that all social mechanisms are at the individual level. ${ }^{5}$ Therefore, analytical sociologists' main argument in support of the implication between both principles would not hold and, consequently, their initial position regarding the question of components would not be justified. Those authors claim that a mechanism for a social macro-phenomenon does not have to be exclusively composed of individuals, their properties, actions, and relations. It must be composed of organized entities and activities, but those need not be only individuals, their properties, actions, and relations. Macro social mechanisms (i.e. social mechanisms that have components of a level higher than the individual level) are possible. Their component entities are either collective agents (e.g. firms, political parties, universities...) and individuals or just collective agents. A paradigmatic example of macro social mechanism is firms competing for market shares in a competitive market. It is composed of firms, their properties (e.g. reputation), activities (e.g. launching an advertising campaign), and relations (e.g. trade partnership). Other illustrative examples of macro social mechanisms would be a coalition of political parties, a conflict between trade unions, or states allied against an environmental problem.

\footnotetext{
${ }^{4}$ It is generally accepted that structural individualism does not imply the principle of mechanism-based explanations (Ylikoski 2011). Explanations of social macro-phenomena in terms of individuals' interactions are possible even if the mechanisms responsible for them are not specified.

${ }^{5}$ This idea was originally introduced by Stinchcombe (1991) (although he understood mechanisms as abstract entities). Stinchcombe held that, in social mechanisms, units of analysis can be individuals, social actors, situations, or patterns of information. He argued that, while units of analysis are generally at a lower level than the explanandum, they do not need to be individuals.
} 
The previously analysed discussion could be briefly summarized as follows. The two fundamental principles of analytical sociology are the principle of mechanism-based explanations and the structural individualism. Analytical sociologists consider that the principle of mechanistic explanations implies structural individualism because there are social mechanisms only at the individual level. The commitment to structural individualism leads to their initial position regarding the question of components: a social mechanism in an explanation of a social macro-phenomenon must be composed of individuals, their properties, actions, and relations to one another. However, as it has been argued, not all social mechanisms are at the level of individuals and, consequently, the principle of mechanistic explanations hardly implies by itself structural individualism. Therefore, the analytical sociology's initial position would not be properly supported.

Given the critiques against the analytical sociology's initial position regarding the question of components, different answers have been raised by analytical sociologists. In the next two sections, I will analyse the main responses: the proposal of Michael Schmid (2011), who supports the analytical sociology's initial position by means of a new argument, and the proposal of Petri Ylikoski (2012), who defends a perspectival version of that position. It will be argued that both of them are unable to offer a proper answer to the question of components.

\section{The new argument by Schmid}

Schmid (2011) maintains the analytical sociology's initial position regarding the question of components. He claims that a social mechanism in an explanation of a social macro-phenomenon must be composed of individuals, their properties, actions, and relations to one another. He also adopts the principle of structural individualism regarding mechanism-based explanations, which leads to that position in relation to the question of components. However, his argument in support of that principle is not based on the idea that there are social mechanisms only at the individual level. He considers that mechanistic explanations of social macro-phenomena require mechanisms at the individual level, but he does not explicitly deny the existence of social mechanisms at other levels.

Firstly, Schmid claims that one aspect of mechanism-based explanations in social science is that they require "laws indicating which factors ultimately 'produce' or 'generate' a relevant event" (2011, p. 137). Specifying nomological connections is necessary in mechanistic explanations. Following the covering-law theory of explanation (Hempel 1965), he argues that the explanandum social macrophenomenon must be deduced from the explanans by means of laws. Although Schmid does not make it explicit, the acknowledged influence of the Hempelian approach suggests that he is understanding laws in a similar way as Hempel does, i.e., as true lawlike statements. And secondly, Schmid argues that we do not know any social law, i.e., a law governing the course of social macro-processes (e.g. a developmental law of society). All candidates to social laws have been proved to be false. In social sciences, only laws of individual action are available. Those laws address how individuals determine their actions in view of their established goals and subjective information. From those ideas, Schmid concludes the principle of structural individualism regarding mechanism-based explanations. He claims that "social phenomena may be regarded as having been explained only when their genesis, operation and reorganization (in the last 
instance) is accounted for on the basis of the individual adaptive actions of individual actors" (Schmid 2011, p. 144). Structural individualism, as it has been noted, leads to the analytical sociology's initial position regarding the question of components.

Schmid's argument in support of the principle of structural individualism in relation to mechanismbased explanations may be reconstructed as follows:

(1) Mechanism-based explanations of social macro-phenomena must include laws.

(2) In social science, the only laws available range over individuals, their properties, actions, and relations.

Mechanistic explanations of social macro-phenomena must refer to individuals, their properties, actions, and relations.

It is a valid argument. The truth of the premises supports the truth of the conclusion. If its premises were true, it would follow the principle of structural individualism regarding mechanism-based explanations. However, I think that one of the premises of the argument is probably not true. The first premise, which is supposed to present a trait of mechanism-based explanations, is likely to be inaccurate. Although subsumption under laws is a requirement in the traditional covering-law model of scientific explanation, mechanistic explanations are not required to include laws (Halina 2018). ${ }^{6}$ In fact, the mechanistic account of scientific explanation has been developed as an alternative to those accounts that require to specify laws (Betchel and Abrahamsen 2005; Hedström 2005). One of the main critiques against the covering-law model was that few or no laws are known in several fields of science (Scriven 1959). That model focuses on certain domains of physics, where many laws are known, and ignores the absence of laws in fields such as biology, sociology, economics, psychology, neuroscience, etc. The mechanistic account of scientific explanation aims to account for explanations in those fields where laws are not available. Therefore, not requiring to indicate laws is a characteristic trait of mechanism-based explanations. In a mechanistic explanation, the explanandum is explained by uncovering the mechanism that is responsible for it, and specifying laws is not required for that. It is not necessary to demonstrate that activities in which mechanisms' component entities engage are according to laws. ${ }^{7}$ Those activities are often characterized just as processes that involve change through time (Glennan 2017) or happenings that produce changes (Machamer 2004). In fact, most mechanism-based explanations do not include laws. For instance, consider Michael Mann's (2004) analysis of the success of European fascism in the interwar period. In his analysis, Mann addresses the property of certain countries (e.g. Britain, France, Sweden...) of not being susceptible to fascist movements seizing power. He offers a mechanism-based explanation of this social macro-property. That explanation refers to a mechanism whose main components are the political parties of those countries and some of their properties, such as subscribing "an instrumental rationality of means not ends" (Mann 2004, p. 90) and

\footnotetext{
${ }^{6}$ Karl-Dieter Opp (2005) has argued that mechanistic explanations must include laws because "[o]nly a law provides a selection criterion for the factors that have caused a phenomenon" $(2005$, p. 174$)$ and without them the election of explanatorily relevant factors is arbitrary. Nevertheless, new mechanists have raised several alternative criteria of explanatory relevance in mechanistic explanations. For instance, Carl Craver (2007, p. 153) has introduced the requirement of mutual manipulability and Stuart Glennan (2017, p. 43) has proposed the requirement of contributing to the activity of the mechanism as a whole.

${ }^{7}$ In the first version of his notion of mechanism, Glennan (1996) considered that interactions among parts of mechanisms must be according to direct causal laws. Nevertheless, Glennan $(2002,2017)$ has later modified his characterization of interactions among mechanisms' parts and removed that requirement.
} 
being accustomed to "[c]eding sovereign powers to the opponent if electorally defeated" (Mann 2004, p. 90). Mann shows that those properties were relevant with respect to the countries' property of not being susceptible to fascist movements seizing power. Nonetheless, Mann's explanation does not include any law. He does not specify a nomological connection between political parties' properties and countries' susceptibility to fascist movements seizing power. The absence of laws in mechanistic explanations is common to most fields of science. Paradigmatic examples of neuroscientific mechanistic explanations (e.g. explanation of neurotransmitter release), for example, do not include laws either (Craver 2007).

As a matter of fact, the idea that mechanism-based explanations must include laws would not even be accepted by most analytical sociologists. They consider that mechanistic explanations are an alternative to covering-law explanations (see section 2) and do not require specifying laws. In this sense, Hedström and Ylikoski say: "Of course, mechanism-based explanations still rely on causal generalizations about the properties, activities, and relations of underlying entities, but they do not have to satisfy the traditional criteria for laws" (2010, p. 55).

Summing up, Schmid adopts a conservative strategy in response to the critiques against the analytical sociology's initial position regarding the question of components. He presents a new reasoning in support of that position, which is also based on the adoption of the principle of structural individualism. His proposal avoids the previously criticized idea that there are social mechanisms only at the individual level. However, his new argument in support of structural individualism is built on a very problematic premise: mechanistic explanations must include laws. As it has been noted, it is unlikely to be the case that mechanism-based explanations are required to specify laws. Schmid fails to justify the principle of structural individualism regarding mechanism-based explanations. Therefore, his proposal does not properly support the analytical sociology's initial position regarding the question of components. Schmid does not offer a justified answer to the question of components.

\section{The perspectival version by Ylikoski}

Unlike Schmid, Ylikoski (2012) advocates a modified version of the analytical sociology's initial position regarding the question of components. In his proposal, the initial demand of individual-level components is replaced by a demand of micro-level components. Micro-level components can but not need to be at the level of individuals. The micro level is perspectival in the sense that it is dependent on the explanatory target.

Analytical sociologists usually consider that all mechanistic explanations of social macrophenomena are causal explanations (Hedström 2005; Hedström and Ylikoski 2010; Demeulenaere 2011). In this sense, Hedström claims that " $[\mathrm{t}]$ he core idea behind the mechanism approach is that we explain [...] by specifying mechanisms that show how phenomena are brought about" (2005, p. 24). However, Ylikoski $(2012$, 2013) has recently argued that mechanistic explanations of social macro-phenomena may be constitutive explanations too. Ylikoski considers that both causal and constitutive explanations "track networks of counterfactual dependence" (Ylikoski 2012, p. 34). The explanans must be a difference-maker with respect to the explanandum. $\mathrm{X}$ explains $\mathrm{Y}$ if $\mathrm{Y}$ depends on $\mathrm{X}$ in the sense that if $\mathrm{X}$ had not happened, 
Y would have not happened either (Woodward 2003; Ylikoski 2013). Nevertheless, causal and constitutive explanations track different sort of counterfactual dependencies: "[c]ausal explanations appeal to etiological counterfactuals, while constitutive counterfactuals are the material for constitutive explanations" (Ylikoski 2013, p. 290). Although both causation and constitution are relations of dependence, there are relevant metaphysical differences between them. Causation is often a relation between events (i.e. changes in the properties of entities), takes time, and is asymmetric regarding manipulation (i.e. a change in the effect can be produced by manipulating the cause, but not the other way around). Constitution is often a relation between causal capacities (i.e. properties of entities), is synchronic, and is symmetric regarding manipulation (i.e. a change in the whole can be produced by manipulating a part of it, and vice versa). Causal explanations include parts of the causal history of the explanandum event that are causally relevant for it (i.e. there are causal counterfactuals that relate them), while constitutive explanations include parts of the system whose property is the explanandum that are constitutively relevant for it (i.e. there are constitutive counterfactuals that relate them). Ylikoski (2013, p. 291) considers that both causal and constitutive explanations can be mechanistic if they tell why and how the counterfactual dependencies hold. Causal mechanism-based explanations must specify the mechanism that brings about the explanandum event, whose components are causally relevant for it, and constitutive mechanism-based explanations must specify the mechanism that gives rise to the explanandum property, whose components are constitutively relevant for it. ${ }^{8}$

Taking the distinction between constitutive and causal mechanism-based explanations as reference, Ylikoski addresses the question of components. Firstly, he focuses on constitutive mechanistic explanations of social macro-phenomena. Ylikoski considers that "[ $\mathrm{t}]$ he explanantia in constitutive explanations are always at the micro level" (Ylikoski 2012, p. 35). Constitutive explanations aim to show how explanandum macro-phenomena "are constituted by micro-level entities, activities and relations" (Ylikoski 2012, p. 35). Consequently, he claims that the components of social mechanisms in constitutive mechanism-based explanations of social macro-phenomena must be located at the micro level. Secondly, Ylikoski addresses causal mechanistic explanations of social macro-phenomena. He acknowledges that the explanantia in causal explanations are not always at the micro level. Unlike the notion of composition, "nothing in the notion of causation implies that the real causal work is always to be found at the micro level" (Ylikoski 2012, p. 36). Causally relevant entities, properties, activities, and relations do not need to be at the micro level. For example, the marketing strategy of a courier firm is causally relevant (i.e. there are causal counterfactuals that relate them) for the market shares of other firms that provide courier services in the same area. Nevertheless, Ylikoski considers that causal mechanistic explanations of social macrophenomena require microfoundations. Appealing to micro-level entities, properties, activities, and relations is essential for understanding how the explanatory counterfactual dependencies hold. Consequently, he argues that the components of social mechanisms in causal mechanism-based explanations of social macrophenomena must be located at the micro level. Ylikoski concludes that, despite their relevant differences,

\footnotetext{
${ }^{8}$ Several new mechanists (e.g. Craver 2007) consider that the explanandum of a constitutive mechanistic explanation is a behaviour of a system. However, Ylikoski (2013) argues that the notion of behaviour can refer to both properties and events, and is potentially confusing. He claims that explananda of constitutive mechanism-based explanations must be characterized as properties of entities.
} 
in both constitutive and causal mechanistic explanations of social macro-phenomena, social mechanisms must be composed of micro-level entities, properties, activities, and relations.

Ylikoski's proposal is less rigid than the analytical sociology's initial position regarding the question of components. He holds that components of social mechanisms in mechanism-based explanations of social macro-phenomena must be micro-level entities, properties, activities, and relations. Nonetheless, he considers that there is not a unique and predetermined micro level (e.g. the individual level) to which components of social mechanisms must always belong. The distinction between micro and macro is understood as a question of scale: "the difference between small- and large-scale social phenomena" (Ylikoski 2012, p. 27). What is considered as micro-level entities, properties, activities, and relations depends on the explanandum phenomenon (and the explanatory interests). A component could be considered micro regarding certain social phenomenon but not regarding another one. As an example, take into account regional governments. A regional government would be considered a micro entity regarding the gross domestic product of a country but not regarding the performance of town councils. Although micro-macro relations involve differences in scale, all differences in scale do not constitute legitimate micro-macro relations. For instance, between people's literary preferences and countries' migration policies there is a difference of scale, but it hardly constitutes a micro-macro relation. Nonetheless, Ylikoski acknowledges that it is difficult to identify the additional traits that characterise legitimate social micromacro relations and differentiate them from other differences in scale. He considers that it is only possible to underline some traits that are often present in social micro-macro relations. For example, many social micro-macro relations are part-whole relationships and macro social facts are usually supra-individual.

Ylikoski's perspectival version avoids the main difficulty of the analytical sociology's initial approach to the question of components. It is compatible with the fact that not all social mechanisms are at the individual level. In that proposal, it is considered that micro components of social mechanisms may be at different levels. Ylikoski's approach also avoids the problem of Schmid's argument. In it, it is not required that mechanism-based explanations of social macro-phenomena include laws. Nevertheless, the perspectival proposal developed by Ylikoski faces some relevant difficulties.

The main problem of Ylikoski's proposal is that it is too vague and, consequently, does not constitute a proper answer to the question of components. In order to avoid the problem of the analytical sociology's initial position, the requirement of individual-level components is substituted by the requirement of microlevel components. Nevertheless, the notion of micro level is not accurately characterised. The micro-macro relation is defined as a particular kind of difference in scale. But the traits that characterise it and distinguish it from other differences in scale are not identified. It is always ambiguous whether the components of a social mechanism are at the micro level and meet the requirement.

Another problematic aspect of Ylikoski's proposal is that it does not provide a guide for building mechanism-based explanations of social macro-phenomena. Firstly, as it has been noted, it is not concrete enough. It is never certain if a particular entity, property, activity or relation is at the micro level. And secondly, the identification of the micro level would require the previous specification of the explanans and the explanandum. In order to belong to the micro level, a component must be explanatorily relevant for the explanandum macro-phenomenon. In this sense, Ylikoski says: "Macro-level facts are explained by 
appealing to micro-level processes, entities, and relations, but these items belong to the micro level just because they are required for the full explanation of the macro fact" (2012, p. 25). Consequently, it would not be possible to identify which entities, properties, activities, and relations are at the micro level before the development of the explanation.

Finally, despite being less rigid than analytical sociology’ initial approach, Ylikoski’s proposal does not suit many mechanism-based explanations of social macro-phenomena. In social science, causal mechanistic explanations of social macro-events often include causal relevant entities, properties, activities, or relations that are unlikely to be at the micro level. An example can be found in Aaron M. McCright and Riley E. Dunlap's (2003) analysis of the conservative movement's impact on the United States climate change policy. They provide a causal mechanism-based explanation of the no ratification of the Kyoto Protocol by the United States senate. Conservative movement saw the concern over global warming as threatening American industry, prosperity, and lifestyle. It considered that changes resulting from efforts to ameliorate the global warming would harm American economy. Because of those worries, conservative think tanks (e.g. Cato Institute, Heritage Foundation, Marshall Institute...) challenged the legitimacy of global warming as a problem by means of diverse strategic activities, such as publishing documents (e.g. policy studies), producing advertisements, presenting their global warming counter-claims to policy makers in Congressional hearings, and appearing on television programs. Their activities and their collaboration with American climate change sceptics eventually produced a redefinition of global warming as nonproblematic. That redefinition influenced in the policy arena and brought about the no ratification of the Kyoto Protocol by the United States senate. In McCright and Dunlap's causal mechanism-based explanation, most components of the social mechanism are hardly at the micro level. Firstly, there is not a clear difference in scale between them and the explanandum macro-phenomenon. For instance, consider think thanks' challenge of the legitimacy of global warming as a problem. It does not seem reasonable to consider it a small-scale activity and the no ratification by the senate a large-scale phenomenon. Both are supra-individual events, and there is no relevant difference between them that supports that differentiation. And secondly, even if there was a difference in scale between them, the relation between the components of the mechanism and the explanandum would hardly constitute a meaningful micro-macro relation. The traits that usually characterise micro-macro relations are not present there. For example, there is not a partwhole relationship between them. United States conservative movement, American network of climate change sceptics, and think thanks are not part of the United States senate.

In summary, Ylikoski defends a modified version of the analytical sociology's initial position regarding the question of components. The requirement of individual-level components is substituted by the requirement of micro-level components. He claims that components of social mechanisms in mechanism-based explanations of social macro-phenomena must be micro-level entities, properties, activities, and relations. That proposal avoids the problems of the analytical sociology's initial position and of the Schmid's argument. Nevertheless, it faces relevant difficulties. As it has been argued, it is too vague, it does not provide a guide for building mechanism-based explanations, and it does not suit many causal mechanistic explanations of social macro-phenomena. Ylikoski does not offer a satisfactory answer to the question of components either. 


\section{A minimal requirement}

Analytical sociologists' proposals regarding components of social mechanisms in explanations of social macro-phenomena face outstanding difficulties. Nevertheless, I consider that it is possible to offer a proper response to the question of components. The aim of this section is to present a minimal requirement regarding the components of social mechanisms, which applies to both causal and constitutive mechanistic explanations of social macro-phenomena.

Mechanism-based explanations of social macro-phenomena can be causal or constitutive explanations (Ylikoski 2012, 2013). In a mechanistic explanation, the explanandum phenomenon is explained by specifying the mechanism that is responsible for it. But the relation between the explanandum social macro-phenomenon and the social mechanism responsible for it may be causal or constitutive. Causal mechanistic explanations of social macro-phenomena include parts of the causal history of the explanandum that are causally relevant for it, while constitutive mechanistic explanations include parts of the system whose property or behaviour is the explanandum that are constitutively relevant for it. An example of a causal mechanistic explanation of a social macro-phenomenon is Salganik, Dodds, and Watts' (2006) explanation of inequality of success in cultural markets (see section 2). They specify how the behaviour of individual consumers, which is socially influenced, brings about that inequality. Other examples of causal mechanistic explanations are McCright and Dunlap's (2003) explanation of the failure of the United States to ratify the Kyoto Protocol, and Katherine Stovel and Christine Fountain's (2009) explanation of the persistence of segregation in the labour market. An example of a constitutive mechanistic explanation of a social macro-phenomenon is Mann's (2004) explanation of the property of certain European countries of not being susceptible to fascist movements seizing power (see section 3). He specifies how certain properties of the components of those countries (e.g. political parties) constituted the property of interest. Other examples of constitutive mechanistic explanations could be a mechanistic explanation of a property of a parliament (e.g. liberals having an absolute majority), and a mechanistic explanation of the differences in the problem-solving capacities of two groups (Ylikoski 2012).

There is no privileged level to which components of social mechanisms in mechanistic explanations of social macro-phenomena must always belong. Neither in causal mechanism-based explanations nor in constitutive mechanism-based explanations of social macro-phenomena, must components of social mechanisms always be at certain fixed level. Both causally relevant components and constitutively relevant components may be at diverse levels. As a matter of fact, components of social mechanisms included in mechanistic explanations of social macro-phenomena are not always at the same level. Consider Salganik, Dodds, and Watts' (2006) and McCright and Dunlap's (2003) causal mechanism-based explanations. Salganik, Dodds, and Watts refer to a mechanism whose components are at the individual level (e.g. individual consumers), while McCright and Dunlap refer to a mechanism whose main components are collective agents (e.g. think tanks). The same diversity can be found in constitutive mechanism-based explanations. Constitutive mechanistic explanations of the problem-solving capacity of a group refer to

mechanisms whose components are at the individual level (e.g. social skills of individual members of the 
group), while constitutive mechanistic explanations of a property of a parliament often refer to mechanisms whose main components are collective agents (e.g. parliamentary groups) and their properties.

Given this scenario, it could be considered that a proper answer to questions of components is hardly achievable. It seems that proposals that account for the diversity of mechanistic explanations of social macro-phenomena (as Ylikoski's proposal) are too vague and unable to provide a guide for building mechanism-based explanations, while concrete and operational proposals (as analytical sociology's initial position) do not suit the diversity of mechanistic explanations of social macro-phenomena. Nonetheless, I think that a minimal requirement, which is concrete and operational without neglecting the diversity of mechanism-based explanations, can be raised regarding the components of social mechanisms. Particularly, a component of a social mechanism in a mechanistic explanation of a social macro-phenomenon must not have the explanandum phenomenon as a part of it. This minimal requirement is concrete enough and provides a guide for building mechanism-based explanations of social macro-phenomena. The identification of parts does not require the previous specification of the explanans and the explanandum. Moreover, the minimal requirement applies to both causal and constitutive mechanism-based explanations of social macro-phenomena.

In a causal mechanism-based explanation of a social macro-phenomenon, components of the mechanism must not have the explanandum phenomenon as a part of them. In order to be a component of the mechanism, an entity or an activity (or another kind of component) must be causally relevant for the explanandum phenomenon. An entity or an activity is causally relevant for a phenomenon if there is a relation of causal dependence between them (i.e. there are causal counterfactuals that relate them) (Woodward 2003; Ylikoski 2012). However, there cannot be a relation of causal dependence between an entity or an activity and the explanandum phenomenon if the former has the phenomenon as a part of it. A relation of causal dependence is not possible between a whole and one of its parts. ${ }^{9}$ It is generally agreed that, in a relation of causal dependence, the relata must be wholly distinct (Hitchcock 2003; Craver and Bechtel 2007; Ehring 2009). Causes and effects must be able to be conceived as independent existences. In this sense, Lewis claims: " $\mathrm{C}$ and $\mathrm{E}$ must be distinct events - and distinct not only in the sense of nonidentity but also in the sense of nonoverlap and nonimplication" (2000, p. 78). Furthermore, causal dependence demands certain requirements that are not satisfied in whole-part relations. For instance, the relation of causal dependence must be asymmetric regarding manipulation and take time (i.e. the relation must not be synchronic) (Craver 2007; Ylikoski 2013). Consequently, in a causal mechanism-based explanation of a social macro-phenomenon, an entity or an activity (or another kind of component) that has the explanandum phenomenon as a part of it cannot be a component of the mechanism.

\footnotetext{
${ }^{9}$ Apparent cases of whole-part (or part-whole) causal relation can be finer understood as causal interactions among parts associated with one or more constitutive relations (Craver and Bechtel 2007). For instance, many putative wholepart causal relations can be analysed as a particular constellation of states of parts, which constitutes certain state of the whole, that causes changes in some parts. Consider, for example, the apparent causal relation between societies' political polarisation and individuals' discrimination against opposing partisans (Iyengar and Westwood 2015). A society's political polarisation is constituted by the divergence of individuals' political attitudes to ideological extremes. Divergence of political attitudes causes affection toward copartisans and animosity toward opposing partisans, and this affective separation results in discriminatory behaviour (in both political and non-political domains) toward opposing partisans.
} 
Likewise, in a constitutive mechanism-based explanation of a social macro-phenomenon, components of the mechanism must not have the explanandum phenomenon as a part of them either. In that kind of explanations, components of the mechanism must be proper parts (i.e. parts that are non-identical to the whole) of the system whose property or behaviour is the explanandum phenomenon (Craver 2007). Constitutive mechanistic explanations explain the explananda by appealing to how the diverse relevant parts together give rise to them. Nevertheless, a component cannot be a proper part of the system whose property or behaviour is the explanandum phenomenon if that phenomenon is part of it. If the phenomenon of interest is part of a component, the system whose property or behaviour is that phenomenon is also part of it. For example, if the problem-solving capacity of a team is part of a certain firm, the team is also part of that firm. And if the system is part of the component, the component cannot be a proper part of the system. Something cannot be a proper part of one of its parts (e.g. a society cannot be a proper part of one of its members). Therefore, in a constitutive mechanism-based explanation of a social macro-phenomenon, an entity or an activity (or another kind of component) that has the explanandum phenomenon as a part of it cannot be a component of the mechanism.

The proposed minimal requirement constitutes a proper answer to the question of components. Certainly, it does not identify a privileged level (e.g. the level of individuals) to which components of social mechanisms in mechanistic explanations of social macro-phenomena must always belong. As it has been argued, there is no such level. Proposals that seek to identify a privileged level to which components of social mechanisms must always belong are doomed to failure. Nevertheless, the minimal requirement introduces a restriction regarding the relationship between the explanandum social macro-phenomena and components of social mechanisms. A component of a social mechanism in a mechanistic explanation of a social macro-phenomenon must not have the explanandum phenomenon as a part of it. It should be noted that the proposed requirement does not demand that components of social mechanisms in mechanism-based explanations of a social macro-phenomena must be proper parts of the explananda. Certainly, being a proper part of the explanandum social macro-phenomenon is a sufficient condition to satisfy the minimal requirement. A component that is a proper part of the explanandum phenomenon does not have that phenomenon as a part. For example, consider Mann's (2004) mechanistic explanation of the property of certain European countries of not being susceptible to fascist movements seizing power. The components of the social mechanism indicated in the explanation (e.g. political parties' properties), which are proper parts of the explanandum (i.e. countries' properties), meet the minimal requirement. However, being a proper part of the explanandum social macro-phenomenon is not a necessary condition to satisfy the minimal requirement. A component of a social mechanism in a mechanism-based explanation may satisfy the minimal requirement even if it is not a proper part of the explanandum phenomenon. A component of a social mechanism would also meet the minimal requirement if it is not constitutively related with the explanandum phenomenon. A component is not constitutively related with a phenomenon if and only if there is no part-whole relationship between them; neither is the component part of the phenomenon nor is the phenomenon part of the component. For example, consider the components of a social mechanism in a mechanism-based explanation of a change in certain neighbourhood (e.g. a change in its racial composition). Components such as households that do not belong to that neighbourhood (e.g. households 
of other neighbourhoods of the same city), which are not constitutively related with the explanandum phenomenon, would meet the minimal requirement.

The proposed requirement is less restrictive than the analytical sociology's initial position regarding the question of components and the Ylikoski's perspectival version. The minimal requirement allows those mechanistic explanations of social macro-phenomena that suit the analytical sociology's initial proposal or its perspectival version, but also other legitimate mechanistic explanations that do not suit any of them. A mechanistic explanation of a social macro-phenomenon that suits the analytical sociology's initial proposal would surely satisfy the minimal requirement. If components of a social mechanism in an explanation of a social macro-phenomenon are individuals, their properties, actions, and relations, they do not have the explanandum macro-phenomenon as a part of them. Likewise, a mechanistic explanation of a social macrophenomenon that suits the Ylikoski's proposal would satisfy the minimal requirement. If components of a social mechanism in an explanation of a social macro-phenomenon are at the micro level regarding it, they do not have the explanandum macro-phenomenon as a part of them. ${ }^{10}$ Nevertheless, the minimal requirement is also satisfied by other legitimate mechanism-based explanations of social macro-phenomena that do not suit those proposals. For example, consider McCright and Dunlap's (2003) explanation of the failure of the United States to ratify the Kyoto Protocol. This mechanistic explanation of a social macrophenomenon does not suit the analytical sociology's initial proposal. It refers to a mechanism whose components are not just individuals, their properties, actions, and relations to one another. Conservative think tanks are the main component entities of the mechanism. Moreover, as it has been showed (see section 4), that mechanism-based explanation does not suit Ylikoki's perspectival proposal either. It refers to a mechanism whose components are hardly at the micro level. However, McCright and Dunlap's explanation does meet the proposed minimal requirement. The components of the social mechanism referred by McCright and Dunlap (e.g. Cato Institute) do not have the explanandum phenomenon (i.e. the failure of the United States to ratify the Kyoto Protocol) as a part of them.

Advocates of more restrictive answers to the question of components could argue that the proposed minimal requirement is too broad and, consequently, ineffective. However, it is unlikely to be the case. Although the minimal requirement is broader than some alternative proposals (e.g. analytical sociology's initial position), it is not so broad that it is ineffective. The minimal requirement introduces an effective restriction regarding the components of social mechanisms in mechanism-based explanations of social macro-phenomena. It excludes those components that have the explanandum phenomenon as part of them. This restriction is helpful in order to determine if an explanation of a social macro-phenomenon is a legitimate mechanistic explanation. ${ }^{11}$ For example, consider a mechanism-based explanation of a property of the city of London (e.g. a certain degree of economic inequality). If the explanation appealed to a social

\footnotetext{
${ }^{10}$ As it has been argued (see section 4), in Ylikoski's perspectival proposal, micro-macro relations are not accurately characterised. Consequently, it is difficult to precisely compare that proposal with the minimal requirement. Nevertheless, any sensible characterisation of micro-macro relations would exclude the possibility that a macrophenomenon is part of a micro component. So, it is reasonable to compare both proposals in those general terms.

${ }^{11}$ It should be noted that failing to satisfy the minimal requirement does not necessarily mean that an explanation is illegitimate or lacks explanatory power. The minimal requirement aims to distinguish legitimate from non-legitimate mechanistic explanations. If a mechanism-based explanation does not meet the minimal requirement, it cannot be considered a legitimate mechanistic explanation. Nonetheless, an explanation that does not meet the minimal requirement could be a legitimate non-mechanistic explanation. For example, an explanation that accounts for people's attitude in terms of the properties of a group to which they belong could be a legitimate non-mechanistic explanation.
} 
mechanism whose components are neighbourhoods (e.g. Chelsea), their properties, actions, and relations, the explanation would satisfy the minimal requirement and it could be a legitimate mechanistic explanation. However, if England or the United Kingdom, which have London and its properties as parts of them, were among the components of the appealed social mechanism, the explanation would not satisfy the minimal requirement and could not be a legitimate mechanistic explanation.

\section{Conclusion}

The analytical sociology's initial position regarding components of social mechanisms in explanations of social macro-phenomena is that they must be individuals, their properties, actions, and relations to one another. After the critiques against this approach, different answers have been raised by analytical sociologists. Schmid (2011) has formulated a new argument in support of that initial position, while Ylikoski (2012) has proposed a perspectival version of it. Nevertheless, both proposals face outstanding difficulties. The analytical sociology's initial position regarding components of social mechanisms should be given up. There is no privileged level to which components of social mechanisms in mechanistic explanations of social macro-phenomenon must always belong. However, a minimal requirement can be raised with respect to components of social mechanisms, that is, components of social mechanisms in mechanistic explanations of social macro-phenomena must not have the explanandum phenomenon as a part.

The proposed minimal requirement would considerably contribute to the development of the mechanistic account of scientific explanation in social science. Firstly, it offers a unified and justified response to the question of components. In all mechanism-based explanations of social macro-phenomena, components of social mechanisms must satisfy the proposed requirement. Secondly, the adoption of the minimal requirement would make the mechanistic account less narrow and able to account for a greater number of legitimate explanations. This would aid to actualize its will of broad applicability. As it has been noted, the mechanistic account aims to be broader than previous proposals (e.g. covering-law model) and suit many legitimate explanations that are excluded by them. And thirdly, the proposed minimal requirement provides a framework within which more specific non-individualist approaches to mechanismbased explanations in social science could be developed. For example, it could assist the elaboration of actor-based approaches to causal mechanistic explanations (e.g. Ruonavaara 2012). Those approaches are based on the idea that causal mechanistic explanations (especially when the explanandum is an interdependency between social phenomena) have to be in terms of actors, which do not need to be individuals, and their actions and interactions. Examples of actors would be firms, residents, and political parties. 


\section{Acknowledgments}

I would like to thank Marc Artiga, Antonio Gaitán, Valeriano Iranzo, Tuukka Kaidesoja, Aki Lehtinen, Cristian Saborido, David Teira, Petri Ylikoski, and two anonymous reviewers for their helpful comments. This work was supported by the Spanish Ministry of Universities under grant FPU16/03274 and the Spanish Ministry of Science and Innovation under grant FFI2017-89639-P.

\section{References}

Abbott, Andrew. 2007. Mechanisms and relations. Sociologica 1: 1-21.

Bechtel, William, and Adele Abrahamsen. 2005. Explanation: a mechanists alternative. Studies in History and Philosophy of Biological and Biomedical Sciences 36: 421-441.

Bunge, Mario. 1997. Mechanisms and explanation. Philosophy of the Social Sciences 27: 410-465.

Bunge, Mario. 2004. How does it work? The search for explanatory mechanisms. Philosophy of the Social Sciences 34: 182-210.

Craver, Carl F. 2007. Explaining the Brain: Mechanisms and the Mosaic Unity of Neuroscience. Oxford: Clarendon Press.

Craver, Carl F., and William Bechtel. 2007. Top-down causation without top-down causes. Biology and Philosophy 22: 547-563.

Demeulenaere, Pierre. 2011. Introduction. In Analytical Sociology and Social Mechanisms, ed. Pierre Demeulenare, 1-30. Cambridge: Cambridge University Press.

Ehring, Douglas. 2009. Causal Relata. In The Oxford Handbook of Causation, eds. Helen Beebee, Christopher Hitchcock, and Peter Menzies, 387-413. Oxford: Oxford University Press.

Elster, Jon. 1989. Nuts and Bolts for Social Sciences. Cambridge: Cambridge University Press.

Elster, Jon. 2007. Explaining Social Behaviour: More Nuts and Bolts for the Social Sciences. New York: Cambridge University Press.

Glennan, Stuart. 2002. Rethinking Mechanistic Explanation. Philosophy of Science 69: S342-S353.

Glennan, Stuart. 2017. The New Mechanical Philosophy. Oxford: Oxford University Press.

Glennan, Stuart S. 1996. Mechanisms and the Nature of Causation. Erkenntnis 44: 49-71.

Gross, Neil. 2009. A pragmatist theory of social mechanisms. American Sociological Review 74: 358-379.

Halina, Marta. 2018. Mechanistic explanation and its limits. In The Routledge Handbook of Mechanisms and Mechanical Philosophy, eds. Stuart Glennan and Phyllis Illari, 213-224. Abingdon: Routledge.

Hedström, Peter. 2005. Dissecting the Social: On the Principles of Analytical Sociology. New York: Cambridge University Press.

Hedström, Peter, and Peter Bearman (eds.). 2009a. The Oxford Handbook of Analytical Sociology. Oxford: Oxford University Press.

Hedström, Peter, and Peter Bearman. 2009b. What Is Analytical Sociology All About? An Introductory Essay. In The Oxford Handbook of Analytical Sociology, eds. Peter Hedström and Peter Bearman, 3-24. Oxford: Oxford University Press. 
Hedström, Peter, and Richard Swedberg. 1998. Social mechanisms: An introductory essay. In Social Mechanisms: An Analytical Approach to Social Theory, eds. Peter Hedström and Richard Swedberg, 1-31. Cambridge: Cambridge University Press.

Hedström, Peter, and Petri Ylikoski. 2010. Causal Mechanisms in the Social Sciences. Annual Review of Sociology 36: 49-67.

Hedström, Peter, and Petri Ylikoski. 2011. Analytical Sociology. In The SAGE Handbook of The Philosophy of Social Sciences, eds. Ian C. Jarvie and Jesús Zamora-Bonilla, 386-398. London: SAGE Publications.

Hempel, Carl G. 1965. Aspects of Scientific Explanation and Other Essays in the Philosophy of Science. New York: The Free press.

Hitchcock, Christopher. 2003. Of Humean Bondage. The British Journal for the Philosophy of Science 54: 1-25.

Iyengar, Shanto, and Sean J. Westwood. 2015. Fear and Loathing across Party Lines: New Evidence on Group Polarization. American Journal of Political Science 59: 690-707.

Kaidesoja, Tuukka. 2013. Overcoming the Biases of Microfoundationalism: Social Mechanisms and Collective Agents. Philosophy of the Social Sciences 43: 301-322.

Kincaid, Harold. 2004. Contextualism, explanation and social sciences. Philosophical Explorations 7: 201218 .

Lewis, David. 2000. Causation as Influence. The Journal of Philosophy 97: 182-197. Reprinted in Causation and Counterfactuals, eds. John Collins, Ned Hall, and L. A. Paul, 75-105. Cambridge: MIT Press.

Machamer, Peter. 2004. Activities and Causation: The Metaphysics and Epistemology of Mechanisms. International Studies in the Philosophy of Science 18: 27-39.

Mahoney, James. 2001. Beyond Correlational Analysis: Recent Innovations in Theory and Method. Sociological Forum 16: 575-593.

Mann, Michael. 2004. Fascists. New York: Cambridge University Press.

Manzo, Gianluca. 2010. Analytical Sociology and Its Critics. European Journal of Sociology / Archives Européennes de Sociologie 51: 129-170.

Mayntz, Renate. 2004. Mechanisms in the Analysis of Social Macro-phenomena. Philosophy of the Social Sciences 34: 237-259.

McCright, Aaron M., and Riley E. Dunlap. 2003. Defeating Kyoto: The Conservative Movement's Impact on U.S. Climate Change Policy. Social Problems 50: 348-373.

Opp, Karl-Dieter. 2005. Explanations by mechanisms in the social sciences. Problems, advantages and alternatives. Mind \& Society 4: 163-178.

Ruonavaara, Hannu. 2012. Deconstructing Explanation by Mechanism. Sociological Research Online 17: $1-10$.

Salganik, Matthew J., Peter Sheridan Dodds, and Duncan J. Watts. 2006. Experimental Study of Inequality and Unpredictability in an Artificial Cultural Market. Science 311: 854-856. 
Salganik, Matthew J., and Duncan J. Watts. 2009. Social Influence: The Puzzling Nature of Success in Cultural Markets. In The Oxford Handbook of Analytical Sociology, eds. Peter Hedström and Peter Bearman, 315-341. Oxford: Oxford University Press.

Schmid, Michael. 2011. The logic of mechanistic explanations in the social sciences. In Analytical Sociology and Social Mechanisms, ed. Pierre Demeulenaere, 136-153. Cambridge: Cambridge University Press.

Scriven, Michael. 1959. Explanation and Prediction in Evolutionary Theory. Science 130: 477-482.

Stovel, Katherine, and Christine Fountain. 2009. Matching. In The Oxford Handbook of Analytical Sociology, eds. Peter Hedström and Peter Bearman, 365-390. Oxford: Oxford University Press.

Stinchcombe, Arthur L. 1991. The Conditions of Fruitfulness of Theorizing about Mechanisms in Social Science. Philosophy of the Social Sciences 21: 367-388.

Tilly, Charles. 2000. Processes and mechanisms of democratization. Sociological Theory 18: 1-16.

Tilly, Charles. 2001. Mechanisms in political processes. Annual Review of Political Science 4: 21-41.

Tilly, Charles. 2004. Social boundary mechanisms. Philosophy of the Social Sciences 34: 211-236.

Udhen, Lars. 2001. Methodological Individualism: Background, history and meaning. London: Routledge.

Ylikoski, Petri. 2011. Social mechanisms and explanatory relevance. In Analytical Sociology and Social Mechanisms, ed. Pierre Demeulenare, 154-172. Cambridge: Cambridge University Press.

Ylikoski, Petri. 2012. Micro, Macro, and Mechanisms. In The Oxford Handbook of Philosophy of Social Science, ed. Harold Kincaid, 21-45. New York: Oxford University Press.

Ylikoski, Petri. 2013. Causal and Constitutive Explanation Compared. Erkenntnis 78: 277-297.

Vromen, Jack. 2010. MICRO-Foundations in Strategic Management: Squaring Coleman's Diagram. Erkenntnis 73: 365-383.

Wan, Poe Yu-ze. 2012. Analytical Sociology: A Bungean Appreciation. Science \& Education 21: 15451565.

Woodward, James. 2003. Making Things Happen. A Theory of Causal Explanation. Oxford: Oxford University Press. 